\title{
Family-level Coparenting Processes and Child Gender as Moderators of Family Stress and Toddler Adjustment
}

\author{
Amy M. Kolak ${ }^{a, *}$ and Lynne Vernon-Feagans ${ }^{b}$ \\ ${ }^{a}$ Department of Psychology, University of Michigan, Ann Arbor, MI, USA \\ ${ }^{\mathrm{b}}$ School of Education, University of North Carolina, Chapel Hill, NC, USA
}

\begin{abstract}
The goal of this multi-method study was to examine how child gender and coparenting processes influence associations between family stress and toddlers' social adjustment. The participants, 104 dual-earner couples and their 2-year-old children, were videotaped in their home during a freeplay activity. Mothers and fathers completed questionnaires about stress in their roles as partners, workers, and parents and their child's social-emotional adjustment. Consistent with previous research, higher levels of family stress were associated with poorer adjustment for children. Family harmony, represented by warmth and cooperation, was significantly associated with fewer internalizing problems for children even when family stress was considered. Conversely, coparental banter or 'playful humour' between parents moderated the nature of the association between family stress and children's adjustment. Banter between parents was especially protective for girls suggesting that, even in families with toddler-aged children, gender plays an important role in family-level coparenting processes. Future research needs to consider more fully the impact that child characteristics, such as gender, have on the interplay between the family context and children's development. Copyright (C) 2008 John Wiley \& Sons, Ltd.
\end{abstract}

Key words: coparenting; family stress; child gender; toddlers; dualearner couples

\footnotetext{
*Correspondence to: Amy M. Kolak, Department of Psychology, University of Michigan, 530 Church Street, Ann Arbor, MI 48109-1043, USA. E-mail: kolak@umich.edu
} 


\section{INTRODUCTION}

Stressful life events (i.e. family death, parent unemployment, divorce) have frequently been linked to poor outcomes for children (Belsky, 1984; WebsterStratton, 1990); however, common everyday stress (resulting from parents' roles and responsibilities) in the family may also lead to poor outcomes for children (Crnic \& Greenberg, 1990), especially in dual-earner families where mothers and fathers are juggling family and work responsibilities. These everyday stressors might affect children through their impact on parental well-being and parenting practices; however, stress in the family environment may also be directly linked to children's adjustment.

Coparenting and child gender are two factors that may serve to weaken the link between family stress and child adjustment. First, family-level processes, such as coparenting behaviour that is warm and cooperative, may protect children from the negative impact of family stress. Previous research has found that supportive coparenting buffered children against the negative effects of low levels of positive affect (Schoppe, Mangelsdorf, \& Frosch, 2001) and harsh parenting behaviour (Stright \& Neitzel, 2003). Second, child gender may also play an important role in these associations. For example, the patterns of association between marital discord and adjustment differ for boys and girls (Campbell, 2002; Davies \& Lindsay, 2001), with boys being more negatively affected by marital discord than girls. Few studies to date have considered gender in the links between family stress, more broadly, and children's adjustment (see Gaylord, Kitzmann, \& Lockwood, 2003). Moreover, no studies have simultaneously examined family-level coparenting processes and child gender with respect to family stress and children's development. Therefore, this study will examine whether the associations between stress, family processes (i.e. coparenting), and adjustment differ for boys and girls.

\section{Family Stress}

Numerous areas of stress, including the daily hassles of raising children, the difficulties associated with juggling the demands of work and family, and marital discord, have been shown to negatively impact families and children (Crnic, Gaze, \& Hoffman, 2005; Crnic \& Greenberg, 1990; Crouter, Bumpass, Head, \& McHale, 2001; Lee, Vernon-Feagans, Vazquez, \& Kolak, 2003; Reid \& Crisafulli, 1990; Sameroff, Seifer, \& McDonough, 2004). Evidence suggests that examining the accumulation of risks and stressors may be especially relevant in understanding family functioning and child well-being (Hetherington, 1984; Sameroff et al., 2004). In dual-earner families, husbands and wives may experience stress and conflict within the multiple roles they occupy as marital partners, parents, and workers. Although virtually no studies have considered the cumulative impact of stress related to parents' multiple roles and responsibilities on children's adjustment, each-parenting hassles, marital conflict, and work-family overload-has been individually linked to parent functioning, family processes, and children's well-being. For example, parenting stress has consistently been shown to negatively impact parenting (Creasey \& Reese, 1996; Crnic \& Greenberg, 1990; Deater-Deckard \& Scarr, 1996), parent-child interactions (Deater-Deckard \& Scarr, 1996), and children's outcomes (Creasey \& Jarvis, 1994; Crnic et al., 2005). Marital conflict has been linked to less positive 
parenting (Cummings \& Davies, 1996; Owen \& Cox, 1997) and more negative coparenting interactions (McHale, 1995). Moreover, abundant research has also found direct links between marital conflict and less positive outcomes for children (Cummings \& Davies, 1996; Harrist \& Ainslie, 1998; Mahoney, Jouriles, \& Scavone, 1997). Research on work-family role strain has generally focused on the associations between role overload and parent functioning (Barnett, 1994; Barnett, Marshall, \& Pleck, 1992; Crouter et al., 2001; Voydanoff \& Donnelly, 1999); however, given the strong links between parenting stress, marital conflict, and children's adjustment, role overload may be similarly related to children's well-being. The cumulative effect of mothers' and fathers' parenting hassles, marital conflict, and work-family role overload may be related to children's adjustment, such that the children of couples who are under higher levels of stress may be less well-adjusted and may exhibit more internalizing and externalizing problems. Thus, the first aim of this study was to examine links between family stress and toddler adjustment.

\section{Coparenting Processes Within the Context of Triadic Interactions}

As fathers' contributions to children's development have become more appreciated (Lamb, 2004; Tamis-LeMonda \& Cabrera, 2002), researchers have begun to move beyond the exclusive examination of dyadic interactions, specifically parent-child and marital interactions, to consider family interactions involving more than two people. Triadic interactions, involving mother, father, and child, allow us to consider how parents simultaneously parent their child (Cox \& Paley, 2003) and represent family-level coparenting processes. Coparenting has specifically been defined as, how parents behave toward each other in front of their child and how parents support each other in their roles as parents' (Katz \& Gottman, 1996, p. 61). The way in which parents coordinate their efforts and the amount of warmth they exhibit towards each other during these triadic interactions is also worthy of consideration. According to a family systems' perspective, the interactions involving the whole family are not equivalent to the sum of the dyadic interactions (Minuchin, 1974). In fact, whole-family interactions, including coparenting, appear to be distinct from both parent-child and marital interactions even though there is certainly overlap among these family subsystems.

Observed family processes, including coparenting behaviour, have been linked with children's social competence (Brody, Flor, \& Neubaum, 1998; McHale \& Rasmussen, 1998). McHale and Rasmussen (1998) found that coparenting behaviour with infants, along with parental ratings of coparenting behaviour when children were 4 years of age, predicted child adjustment at 4 years of age. Specifically, they found that greater observed hostility and competitiveness between parents and lower family harmony when children were infants were related to teacher reports of children's aggression 3 years later. McHale and Rasmussen also found that a greater discrepancy between the parents' individual parenting within triadic interactions was positively correlated to teachers' reports of children's anxiety. The second aim of the current study was to examine associations between coparenting processes and children's adjustment.

Evidence suggests that family-level coparenting processes are relevant to children's adjustment once other parent, family, or child factors are considered. 
For example, coparenting behaviour explained additional variance in preschoolaged boys' inhibition above and beyond mothers' and fathers' individual parenting (Belsky, Putnam, \& Crnic, 1997). Observed family processes also predicted preschoolers' externalizing problems when maternal well-being and marital quality were considered (McHale \& Rasmussen, 1998). With elementary-age children, Stright and Neitzel (2003) found that supportive coparenting continued to predict children's classroom adjustment after parents' rejecting behaviour was taken into consideration. Brody et al. (1998) reported that families who engaged in harmonious interactions around childrearing displayed parenting practices that enhanced children's development. Taken together, these findings suggest that coparenting processes are important to our understanding of child development and should be considered along with other family factors, such as family stress. Thus, the third aim of this study was to examine the simultaneous contributions of coparenting processes and family stress to children's adjustment.

Coparenting processes may moderate the association between aspects of the family context and child adjustment. For example, Schoppe et al. (2001) examined the interactive effects of coparenting and affect on preschoolers' externalizing problems and found that among families low in positive affect, high levels of supportive coparenting protected children from externalizing problems. Stright and Neitzel's (2003) research considered coparenting as a moderator between parents' rejecting behaviour and children's classroom adjustment. They found strong associations between high levels of parents' rejecting behaviour and poorer classroom adjustment among families low in supportive coparenting. Conversely, high levels of supportive coparenting ameliorated the negative impact of parents' rejecting behaviour on children's poor classroom adjustment such that parents' rejection and children's classroom adjustment were unrelated.

Though positive, warm, and sensitive coparenting has been found to be a mediator and moderator of good outcomes for children (Schoppe et al., 2001; Stright \& Neitzel, 2003), less research has examined the specific strategies that parents may use when parenting their children. One specific strategy that was examined in this paper is the use of humour or positive banter between parents. Very little research has examined humour as part of positive parenting; yet, research conducted by Carstenson, Gottman, and Levenson (1995) and Gottman, Coan, Carrere, and Swanson (1998) provides support for the role that positive affect, and specifically couples' use of humour, during marital interactions may have on predicting marital quality and stability. Similarly here, humour between parents within the context of family interactions may serve a comparable function to offset negative emotions and ultimately lead to more positive family interactions. Previous studies suggest that humour may be part of the overall construct of parental warmth (Lichtenstein et al., 2003) and that humour may play a role in buffering parenting stress, especially for high-risk families (Eisengart, Singer, Fulton, \& Baley, 2003). The current study examined this particular aspect of coparenting as a possible buffer to stress experienced in dual-earner families and moved beyond main effect models to examine whether positive coparenting processes, including humour (coparental banter), lessen the negative impact of family stress on children's adjustment. The fourth aim of this study was to examine the moderating effect of family-level coparenting processes on the association between family stress and children's adjustment. 


\section{Child Gender}

Though research on gender effects for young children is limited, the research in this area generally suggests that parents interact differently with sons and daughters and that they spend differential amounts of time with sons versus daughters (Cox, Owen, Lewis, \& Henderson, 1989; Manlove \& Vernon-Feagans, 2002). Moreover, the differential parenting of sons and daughters has been linked with other family processes, such as marital quality and coparenting (Kerig, Cowan, \& Cowan, 1993; McHale, 1995). However, it is less clear how coparenting processes, family stress, and child gender may interact to contribute to children's outcomes.

Research to date on family processes and child gender has typically focused on how child gender moderates the association between marital discord and school-aged children's adjustment (see Davies \& Lindsay, 2001). Though findings are mixed with some research on interparental conflict showing no differences for boys and girls (e.g. Buehler, Anthony, Krishnakumar, \& Stone, 1997; Jouriles, Bourg, \& Farris, 1991), other research generally supports one of the following models: the male vulnerability model (e.g. Kerig, 1996) or the differential reactivity model (e.g. Johnston, Gonzalez, \& Campbell, 1987). The male vulnerability model claims that boys are more vulnerable to marital discord whereas the differential reactivity model contends that boys and girls may be differentially affected by marital discord such that children's behaviour may be in line with gender differences in prevalence rates of internalizing and externalizing problems (Zahn-Waxler, 1993). Similarly, we might expect different patterns of association for boys and girls between family stress and children's adjustment. In contrast to previous research where these associations were examined to the exclusion of other family-level processes that might serve to protect or exacerbate the effect of family stress on children's adjustment, we were also interested in simultaneously examining the protective effect of positive coparenting processes. To understand how family processes may be related to differences in boys' and girls' early social and behavioural adjustment, a final goal of this study was to examine the role that child gender plays in the associations among family stress, familylevel coparenting processes, and toddler adjustment. Prior research by McHale (1995), examining marital distress and child gender as predictors of family-level processes, found that parents of daughters tended to disengage from each other when under more distress, whereas parents of sons tended to engage in more hostile and competitive coparenting behaviour. Given these findings, we hypothesized that boys would be at a greater risk for poor adjustment than girls in the face of more family stress, especially when parents engaged in less positive coparenting interactions.

In summary, the aims of the current research were (1) to examine whether family stress, as indexed by marital conflict, the daily hassles of caring for children, and job-family role conflict, in dual-earner families was linked to children's adjustment, (2) to examine the associations between family-level coparenting processes and children's adjustment, (3) to simultaneously examine the contributions of child gender, coparenting processes, and family stress to children's adjustment, (4) to examine observed family-level coparenting processes as moderators of the link between family stress and children's adjustment, and (5) to examine child gender as a moderator of the relations among family stress, family-level coparenting processes, and children's adjustment. 


\section{METHOD}

\section{Participants}

The 104 dual-earner families in the present study had a 2-year-old child participating in the Penn State Health and Development Project, a longitudinal study of children who began centre-based daycare before 1 year of age. This study examined a variety of factors that might have an impact on children's early development. Families were recruited from 11 daycare centres in central Pennsylvania before the target child's first birthday. Families were predominantly European-American and 55\% of the families earned between $\$ 60000$ and $\$ 100000$ annually. Parents were highly educated; $76 \%$ had completed at least a bachelor's degree. Fathers worked an average of $45 \mathrm{~h}$ per week (range of 16-70) and mothers worked an average of $38 \mathrm{~h}$ per week (range of 5-75). Fathers were, on average, 36 years old (range of 24-62) and mothers were, on average, 35 years old (range of 24-54). Forty-four percent of the families had one child, $41 \%$ had 2 children, and $15 \%$ had 3 or 4 children. The target children, 56 boys and 48 girls, entered centre-based daycare at the mean age of 3 months and spent an average of $37 \mathrm{~h}$ per week in daycare during their second year of life.

\section{Procedure}

A home visit, approximately $2 \mathrm{~h}$ in length, was conducted within a few months of the target child's second birthday. Mothers and fathers were administered questionnaires about the target child, their relationship, and how they managed various aspects of their lives. Parents were also videotaped playing with their child. A mat was placed on the floor with three toys that included a box of legos, a wooden puzzle, and a lock box with 12 doors each with a different latch. The interviewer asked the parents to sit on the mat with their child and help him or her play with each of the toys. Approximately $15 \mathrm{~min}$ later, the interviewer requested that the family 'work together to put the toys away'. Parental perception data and the videotaped triadic interactions gathered at the child's 24-month home visit were utilized for this study.

\section{Observational Coding of Triadic Interactions: Family-level Coparenting Processes}

The videotapes of the triadic freeplay sessions (with mother, father, and toddler) were coded for coparenting behaviours and mother-to-child and father-to-child behaviours (for descriptive statistics, see Table 1). Independent coders were assigned to rate the coparenting behaviour and the individual parenting behaviour. Mothers' and fathers' individual parenting variables were coded in separate passes through the tapes and parents within the same family were coded by independent coders. Coders took notes as they viewed the freeplay sessions that were, on average, about $20 \mathrm{~min}$ in length and ranged from approximately 15-25 min. After watching the entire videotape, coders rated each couple or parent based on their behaviour across the entire session. Coders were trained on a subsample of tapes and reliability checks were conducted throughout the coding process. Interrater agreement for each of the codes was calculated on approximately $20 \%$ of the triadic interactions. Intraclass correlations, which are often used to assess interrater agreement on rating scales, are reported below. 
Table 1. Descriptive statistics for observational data

\begin{tabular}{llr}
\hline & $M$ & S.D. \\
\hline Coparenting Processes & & \\
Coparental Warmth & 2.50 & 0.95 \\
Cooperation & 1.86 & 0.81 \\
Coparental Banter & 1.77 & 0.79 \\
Parent-to-Child Processes & & \\
Mother-to-Child Involvement & 5.01 & 0.93 \\
Mother-to-Child Warmth & 4.39 & 0.90 \\
Father-to-Child Involvement & 4.51 & 1.09 \\
Father-to Child Warmth & 3.79 & 1.14 \\
\hline
\end{tabular}

Coparenting behaviour: Using the Coparenting and Family Rating System (CFRS; McHale, Kuersten-Hogan, \& Lauretti, 2001) along with a codebook provided by McHale, Cooperation and Coparental Warmth were coded at the level of the dyad. Detailed descriptions of each of these behaviourally anchored scales can be found in McHale et al. (2001) but they are also described briefly below. A third dyadic variable called Coparental Banter that reflected good-natured teasing and humour between the parents during the triadic freeplay interactions (see details below) was also coded.

Cooperation assessed how parents actively supported one another's parenting efforts and interventions with the child through overt actions and verbalizations. Ratings of 1 were given to couples who either carried out their own agendas with the child or did not play together as a family, whereas ratings of 5 were given to couples who created a sense of joint activity and demonstrated multiple, clear instances of facilitation and support of their partner's suggestions. Because of the low frequencies at the extreme ends of this scale (1's and 5's), this variable was recoded to represent a 3-level variable. The intraclass correlation for Cooperation was 0.60 .

Coparental Warmth assessed the amount of warmth and positive affect between parents throughout the triadic interaction where a score of 1 was given to couples who focused exclusively on the child and a rating of 5 was given to couples who truly seemed to connect to each other (i.e. through eye contact and smiles) and enjoyed one another's company. The intraclass correlation for Coparental Warmth was 0.67.

Coparental Banter: Verbal Sparring was the variable originally described by McHale et al. (2001) and, according to McHale, this variable was intended to assess sarcastic and/or hostility-tinged criticism between the parents when playing with their child. As a result of the low frequency of hostility-tinged behaviour in this sample of parents, this variable was not able to be coded. It did become clear from examining the tapes, however, that positive behaviours that involved 'playfulness', 'teasing', and 'humour' between the parents during these triadic interactions with their child were a more common coparenting strategy. Thus, this variable was named Coparental Banter to capture the positive nature of this behaviour between parents (for data to support this reinterpretation, see the Results section). Coparental Banter was coded to represent a 3-level variable rather than a 5-level variable $(1=$ families never engage in any positive ribbing, $2=$ mild, positive ribbing on one occasion, $3=$ more than one instance of positive ribbing). The intraclass correlation for Coparental Banter was 0.56.

Parent-child relationships: Four individual variables, including Mother-toChild Involvement, Father-to-Child Involvement, Mother-to-Child Warmth, and Fatherto-Child Warmth, were coded. These were drawn from the CFRS (McHale et al., 2001) to assess mothers' and fathers' individual interactions with the target 
children during the triadic interactions. These variables were assessed using a 7-point scale and are briefly described below (complete descriptions of these variables can be found in McHale et al., 2001). We must note that McHale's involvement and warmth scales were intended to capture a range of behaviours where a parent rated as a ' 5 ' would be seen as providing an 'optimal' level of warmth or involvement and a parent rated as a ' 7 ' was seen as being overly involved or overly warm. Given the age of the children in this study, however, it seems unlikely that parents of toddler-aged children could be too warm or too involved (and if they are really warm or involved, it is not necessarily detrimental for children of this age). Thus, we have reconceptualized these variables to represent linear constructs where higher scores represent higher levels of involvement or warmth.

Mother-to-Child Involvement and Father-to-Child Involvement ranged from complete disengagement (1) to continuous involvement (7). The intraclass correlation for Parent-to-Child Involvement was 0.89. Mother-to-Child Warmth and Father-to-Child Warmth scores ranged from extreme warmth where parents used speech, touch, and active eye contact throughout the session (7) to parents who were stiff and wooden during interaction with their child (1). The intraclass correlation for Parent-to-Child Warmth was 0.92 .

Family Harmony: Following previous work by McHale (1995), McHale and Rasmussen (1998), and Talbot and McHale (2004), we created a variable representing mutual involvement, warmth, and cooperation called Family Harmony. First, a Total Family Warmth variable was created by standardizing and averaging scores for Mother-to-Child Warmth, Father-to-Child Warmth, and Coparental Warmth. A Mutuality of Involvement variable was created by calculating the absolute difference between Mother-to-Child and Father-to-Child Involvement scores and then this variable was reversed by multiplying it by -1 so that higher scores reflected greater congruence in involvement (or smaller disparities in the two parents' levels of involvement). Finally, Total Family Warmth, Mutuality of Involvement, and Cooperation (see variable description under coparenting) with significant intercorrelations ranging from 0.23 to 0.41 were standardized and averaged to create Family Harmony (Talbot \& McHale, 2004). Coparental Banter was not significantly correlated to each of the variables composited to create Family Harmony; therefore, Coparental Banter appears to represent a unique aspect of the coparenting partnership and was examined as an independent moderator in the current study; however, Family Harmony and Coparental Banter correlated $0.28(p<0.01)$.

\section{Parent Report Measures}

Family Stress was derived by compositing mothers' and fathers' reports across various domains within the family. Children's social-emotional adjustment was assessed through mothers' and fathers' reports, which were then averaged to create three composites, Social Competence, Internalizing Problems, and Externalizing Problems. All of these constructs are described below. Table 2 provides descriptive statistics for all subscales prior to compositing across mothers' and fathers' reports as well as the correlations between their reports.

\section{Family Stress Variables}

Parenting daily hassles: To assess the amount of everyday stress parents felt as a result of parenting and parent-child interactions, a measure designed by Crnic 
Table 2. Descriptive statistics for mothers' and fathers' reports of family stress and child adjustment and correlations between mothers' and fathers' reports

\begin{tabular}{|c|c|c|c|c|c|}
\hline & \multicolumn{2}{|c|}{ Mothers } & \multicolumn{2}{|c|}{ Fathers } & \multirow[t]{2}{*}{$r$} \\
\hline & $M$ & S.D. & $M$ & S.D. & \\
\hline \multicolumn{6}{|l|}{ Family Stress Variables } \\
\hline Parenting Task Hassles & 14.38 & 4.42 & 14.46 & 4.36 & $0.54^{* * *}$ \\
\hline Marital Conflict & 3.73 & 1.33 & 3.64 & 1.08 & $0.35^{* * *}$ \\
\hline Job-Family Role Overload & 3.33 & 0.67 & 2.90 & 0.62 & $0.19^{*}$ \\
\hline \multicolumn{6}{|l|}{ Child Adjustment Variables } \\
\hline Social Competence & 121.29 & 19.89 & 114.67 & 18.23 & $0.34^{* * *}$ \\
\hline Internalizing Problems & 24.38 & 6.67 & 25.38 & 5.97 & $0.27^{* *}$ \\
\hline Externalizing Problems & 27.63 & 8.68 & 27.02 & 7.54 & $0.33^{* * *}$ \\
\hline
\end{tabular}

${ }^{*} p<0.05,{ }^{* *} p<0.01,{ }^{* * *} p<0.001$.

and Greenberg (1990) was administered to mothers and fathers and was composed of two subscales, parenting task hassles and challenging behaviour hassles. For the purposes of this study, we used the parenting task hassles subscale. Parents rated each of the eight items reflecting routine tasks parents often perform (e.g. running extra errands for children and cleaning up after children) on two scales, frequency and intensity. The frequency scale assessed how often a particular item occurred on a 4-point scale ranging from 1 (rarely) to 4 (constantly). The intensity scale assessed how big of a hassle the respondent perceived each item to be on a 5-point scale ranging from 1 (no hassle) to 5 (big hassle). The frequency and intensity scores were highly correlated for mothers and fathers and since the intensity of parenting hassles seems to be, theoretically, of greater relevance to parents' experiences (Crnic et al., 2005), only this scale was used in the current study. A sum score was created by summing across the eight items such that higher scores indicated that parents felt more hassled by parenting tasks ( $\alpha=0.76$ for wives and husbands). Mothers' and fathers' reports were averaged to create one dyadic variable that represented total parenting task hassles.

Job-family role strain: Mothers and fathers completed the Job-Family Role Strain measure developed by Bohen and Viveros-Long (1981) to assess respondents' feelings about the overlap between work- and home-related responsibilities. Overload of role obligations assessed the physical and psychological exhaustion the respondent expressed in regard to completing both work- and home-related responsibilities. Each of the 5 items reflecting this subscale was rated on a 5-point scale ranging from 1 (never) to 5 (always). Examples include: 'I feel I have more to do than I can comfortably handle' and 'I feel I don't have enough time for myself'. Higher scores on this scale represent greater role overload ( $\alpha=0.84$ for wives and 0.82 for husbands). This measure was shown to have good test-retest reliability and convergent validity in that the subscales were related to work hours and number of hours spent on chores (Bohen \& Viveros-Long, 1981). Wives' and husbands' ratings were averaged to create one score reflecting role overload.

Marital quality questionnaire: To assess the functioning and the quality of the marital relationship, a measure developed by Braiker and Kelly (1979) was utilized. Each of the 5 items tapping conflict in the marriage was rated on a 9point scale ranging from 1 (not at all) to 9 (very little or very much). The conflict 
scale measured overt behavioural conflict and communication of negative affect. Examples include: 'how often do you and your partner argue?' and 'when you and your partner argue, how serious are the problems or arguments?' Higher scores on this scale represented greater conflict $(\alpha=0.80$ for wives and 0.68 for husbands). Belsky and Hsieh (1998) found marital conflict to be highly stable across 4 years for husbands and wives. Wives' and husbands' ratings of conflict were averaged to create one dyadic variable of total marital conflict.

The intercorrelations among the composites reflecting parenting task hassles, role overload, and marital conflict were significant and ranged from 0.20 to 0.30 . To create a robust measure of family stress that considered mothers' and fathers' perceptions of stress within the family environment, the three dyadic variables were standardized and averaged. Higher values on the resulting variable, Family Stress $(\alpha=0.84)$, reflected higher levels of stress in the family related to parents' roles and responsibilities.

\section{Child Social/Emotional Adjustment}

Social competence and problem behaviours were assessed using the parent version of the Preschool Socioaffective Profile (LaFreniere, Dumas, Capuano, \& Dubeau, 1992). This measure assesses characteristic patterns of affective expression, social competence, and adjustment difficulties of preschool children during interactions with peers and adults. The questionnaire consists of 80 items. Each item is rated on a 6-point scale ranging from 1 (never) to 6 (always). LaFreniere and colleagues found this measure to have strong convergent validity with the Child Behaviour Checklist (Achenbach \& Edelbrock, 1981) and good test-retest reliability across 2 weeks and 6 months though the correlations were lower across 6 months.

The Social Competence scale is composed of eight 5-item subscales (40 items) assessing the following behaviours and emotions: joy, security, tolerance, integration, calmness, prosocial behaviour, cooperativeness, and autonomy. Representative items include: 'my child laughs easily', 'my child looks directly at you when speaking', and 'my child comforts or assists another child in difficulty'. Alpha reliabilities for the Social Competence scale were 0.93 and 0.92 for mothers and fathers, respectively.

The Internalizing Problems scale is composed of four 5-item subscales (20 items) assessing the following characteristics: depressiveness, anxiousness, isolation, and dependence. Representative items include: 'my child is difficult to console when he/she cries', 'my child is timid/afraid (i.e., avoids new situations)', and 'my child remains apart/isolated from the group'. Respective $\alpha$ 's for mothers' and fathers' reports of Internalizing Behaviours scale were 0.76 and 0.74 .

The Externalizing Problems scale is composed of four 5-item subscales (20 items) assessing the following characteristics: anger, aggressiveness, egotistical behaviour, and oppositional behaviour. Representative items include 'my child is easily frustrated', 'my child hits, bites or kicks other children', and 'my child gets upset when I attend to another child'. Alpha reliabilities for the Externalizing Behaviours scale were 0.86 for mothers and 0.82 for fathers.

Mothers' and fathers' ratings correlated for each of the children's adjustment variables; therefore, their ratings were averaged to create three composites that 
Table 3. Correlations among analysis variables

\begin{tabular}{|c|c|c|c|c|c|}
\hline & $\begin{array}{l}\text { Family } \\
\text { Stress }\end{array}$ & $\begin{array}{l}\text { Family } \\
\text { Harmony }\end{array}$ & $\begin{array}{l}\text { Coparental } \\
\text { Banter }\end{array}$ & $\begin{array}{l}\text { Social } \\
\text { Competence }\end{array}$ & $\begin{array}{l}\text { Internalizing } \\
\text { Problems }\end{array}$ \\
\hline Family Harmony & 0.00 & & & & \\
\hline Coparental Banter & 0.00 & $0.28^{* *}$ & & & \\
\hline Social & $-0.41^{* * * *}$ & 0.14 & 0.14 & & \\
\hline $\begin{array}{l}\text { Competence } \\
\text { Internalizing } \\
\text { Problems }\end{array}$ & $0.31^{* *}$ & $-0.21^{*}$ & -0.07 & $-0.58^{* * * *}$ & \\
\hline $\begin{array}{l}\text { Externalizing } \\
\text { Problems }\end{array}$ & $0.36^{* * *}$ & $-0.19^{*}$ & -0.12 & $-0.53^{* * * *}$ & $0.41^{* * * *}$ \\
\hline
\end{tabular}

${ }^{*} p<0.05,{ }^{* *} p<0.01,{ }^{* * *} p<0.001,{ }^{* * * *} p<0.0001$.

Table 4. Correlations among analysis variables by child gender

\begin{tabular}{|c|c|c|c|c|c|c|}
\hline & $\begin{array}{l}\text { Family } \\
\text { Stress }\end{array}$ & $\begin{array}{l}\text { Family } \\
\text { Harmony }\end{array}$ & $\begin{array}{l}\text { Coparental } \\
\text { Banter }\end{array}$ & $\begin{array}{l}\text { Social } \\
\text { Competence }\end{array}$ & $\begin{array}{l}\text { Internalizing } \\
\text { Problems }\end{array}$ & $\begin{array}{l}\text { Externalizing } \\
\text { Problems }\end{array}$ \\
\hline Family Stress & & -0.08 & -0.05 & $0.51^{* * * *}$ & $0.40^{* *}$ & $0.45^{* * *}$ \\
\hline $\begin{array}{l}\text { Family } \\
\text { Harmony }\end{array}$ & -0.05 & & 0.23 & 0.19 & -0.23 & -0.21 \\
\hline $\begin{array}{l}\text { Coparental } \\
\text { Banter }\end{array}$ & 0.03 & 0.35 & & 0.06 & 0.02 & 0.06 \\
\hline $\begin{array}{l}\text { Social } \\
\text { Competence }\end{array}$ & -0.27 & 0.07 & 0.23 & & $-0.48^{* * *}$ & $-0.59^{* * * *}$ \\
\hline $\begin{array}{l}\text { Internalizing } \\
\text { Problems }\end{array}$ & 0.18 & -0.17 & -0.22 & $-0.75^{* * * *}$ & & $0.39^{* *}$ \\
\hline $\begin{array}{l}\text { Externalizing } \\
\text { Problems }\end{array}$ & 0.25 & -0.17 & $-0.35^{*}$ & $-0.44^{* *}$ & $0.47^{* * *}$ & \\
\hline
\end{tabular}

Correlations for boys $(n=56)$ are above the diagonal and correlations for girls $(n=48)$ are below the diagonal. ${ }^{*} p<0.05,{ }^{* *} p<0.01,{ }^{* * *} p<0.001,{ }^{* * * *} p<0.0001$.

incorporated both parents' perceptions of their child's behaviour. The variables, Social Competence, Internalizing Problems, and Externalizing Problems, were internally consistent (social competence, $\alpha=0.94$, internalizing problems, $\alpha=0.74$, and externalizing problems, $\alpha=0.87$ ), and though the composites were significantly intercorrelated (see Table 3), we retained three separate composites because they represent theoretically distinct constructs.

\section{RESULTS}

Preliminary analyses did not reveal mean differences between boys and girls on the study variables, including family stress, family harmony, coparental banter, social competence, internalizing problems, or externalizing problems. Owing to our interest, however, in examining child gender as a moderator in the current study, descriptive statistics and intercorrelations among the study variables by child gender can be found in Table 4 . 
Table 5. Regression models predicting child adjustment with child gender, family harmony, and family stress

\begin{tabular}{lcccc}
\hline Models and predictors & $\beta$ & S.E. $B$ & Total $R^{2}$ & $F(3,100)$ \\
\hline Social Competence & 0.07 & 2.82 & 0.18 & $7.50^{* * *}$ \\
$\quad$ Child Gender & 0.11 & 2.26 & & \\
$\quad$ Family Harmony & $-0.40^{* * *}$ & 2.03 & & \\
$\quad$ Family Stress & 0.00 & 0.94 & 0.13 & $4.95^{* *}$ \\
Internalizing Problems & $-0.19^{*}$ & 0.75 & & \\
$\quad$ Child Gender & $0.30^{* *}$ & 0.68 & & \\
$\quad$ Family Harmony & & & 0.19 & $7.65^{* * *}$ \\
$\quad$ Family Stress & $-0.17^{\dagger}$ & 1.19 & & \\
Externalizing Problems & $-0.17^{\dagger}$ & 0.96 & & \\
$\quad$ Child Gender & $0.36^{* * *}$ & 0.86 & & \\
$\quad$ Family Harmony & & & \\
Family Stress & & &
\end{tabular}

${ }^{\dagger} p=0.06,{ }^{*} p=0.05,{ }^{* *} p<0.01,{ }^{* * *} p<0.001$.

\section{Associations Between Family Stress and Child Adjustment}

To address the first aim of the study, bivariate correlations were conducted to examine the relationships between family stress and children's outcomes. As reported in Table 3, family stress was negatively related to children's social competence and positively associated with internalizing problems and externalizing problems.

\section{Associations Between Family-level Coparenting Processes and Child Adjust- ment}

To address the second aim of the study, bivariate correlations were conducted to examine the relationships between family-level coparenting processes and children's adjustment. As reported in Table 3, family harmony was negatively associated with children's internalizing and externalizing problems. Coparental banter was not significantly related to children's adjustment.

\section{Family Stress, Family-level Coparenting Processes, and Child Gender as Predictors of Child Adjustment}

To understand the simultaneous contributions of child gender, familylevel coparenting processes, and family stress to child adjustment (aim 3), a series of regression models were tested. Six models were tested; one for each family-level coparenting process (i.e. family harmony and coparental banter) was run with each of the child adjustment variables (i.e. social competence, internalizing problems, and externalizing problems) as outcomes. As reported in Table 5, all of the models containing family harmony were significant. Family stress emerged as a significant predictor in each of these models. Family harmony was also a significant predictor of children's internalizing problems and a marginally significant predictor of externalizing problems. All of the models that contained coparental banter were significant (see Table 6). Though family stress was significant in each of the models, coparental banter was not a significant predictor of children's outcomes when considered simultaneously. 
Table 6. Regression models predicting child adjustment with child gender, coparental banter, and family stress

\begin{tabular}{lcccc}
\hline Models and predictors & $\beta$ & S.E. $B$ & Total $R^{2}$ & $F(3,100)$ \\
\hline Social Competence & 0.05 & 2.83 & 0.19 & $7.66^{* * *}$ \\
$\quad$ Child Gender & 0.13 & 1.79 & & \\
$\quad$ Coparental Banter & $-0.41^{* * *}$ & 2.02 & & \\
$\quad$ Family Stress & & & 0.10 & $3.72^{*}$ \\
Internalizing Problems & 0.01 & 0.96 & & \\
$\quad$ Child Gender & -0.07 & 0.61 & & \\
$\quad$ Coparental Banter & $0.31^{* *}$ & 0.69 & \multirow{2}{*}{0.17} & \\
$\quad$ Family Stress & -0.16 & 1.21 & & \\
Externalizing Problems & -0.10 & 0.77 & & \\
$\quad$ Child Gender & $0.37^{* * *}$ & 0.87 & & \\
$\quad$ Coparental Banter & & & \\
Family Stress & & &
\end{tabular}

${ }^{\dagger} p=0.06,{ }^{*} p=0.05,{ }^{* *} p<0.01,{ }^{* * *} p<0.001$.

\section{Family Stress, Family-level Coparenting Processes, and Child Gender as Predictors of Child Adjustment: Interactive Models}

To address aims 4 and 5, which were to examine the interactive effects of child gender, family-level coparenting processes, and family stress on children's adjustment, we added a second step to the regression models above, which included four interactions terms (i.e. the three possible two-way interactions and the three-way interaction). ${ }^{1}$ This approach allowed us to examine whether family-level coparenting processes and child gender moderated the associations between family stress and children's adjustment. Therefore, three two-way interaction terms were included in Step 2: family stress $\times$ family harmony (or coparental banter), family stress $\times$ child gender, and family harmony (or coparental banter) $\times$ child gender. The three-way interaction term, also entered in Step 2, was family stress $\times$ family harmony (or coparental banter) $\times$ child gender.

To reduce multicollinearity and increase interpretability, the continuous variables-family stress and coparental banter-were centred by subtracting the corresponding mean for the variable prior to creating the interaction terms (see Aiken \& West, 1991). Because family harmony was created from standardized variables, it had a mean of zero and, thus, did not need to be centred. Significant interactions were graphed using high and low values (+1 and -1 standard deviation of the mean) of each of the variables in the interaction term. Following the procedures outlined by Aiken and West (1991), simple slope analyses were conducted to test whether each of the plotted regression lines was significantly different from zero. A slope significantly different from zero indicates that for a particular level of the interaction variable, there is a strong relationship between the independent and dependent variables.

The interactive regression models involving coparental banter revealed one significant two-way interaction and one three-way interaction. A three-way interaction, family stress by coparental banter by child gender, was significant for internalizing problems, $B=-3.34$, S.E. $=1.65, t=-2.01, p<0.05$, overall $R^{2}=0.19, F(7,96)=3.30, p<0.01$. As Figure 1 shows, there was a significant positive association between family stress and internalizing problems for sons whose parents engaged in low levels of coparental banter $(\beta=0.43, p<0.01)$ and 


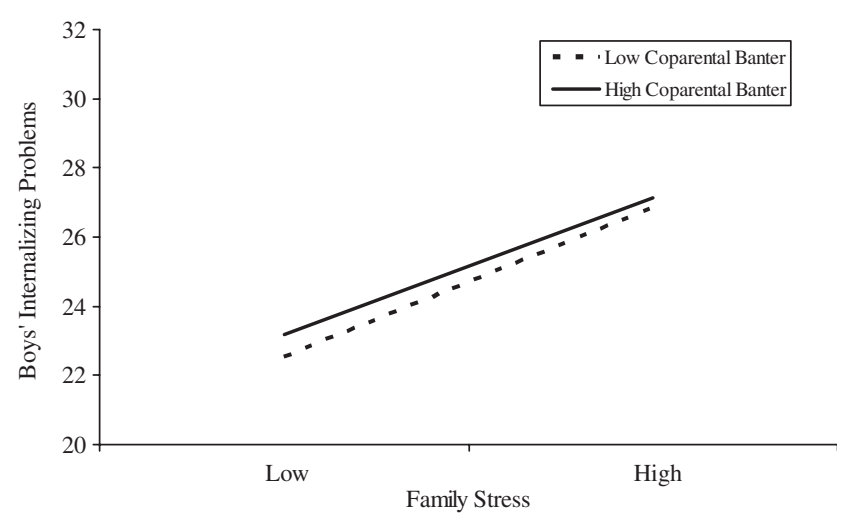

Figure 1. The interaction between family stress and coparental banter for sons' internalizing problems.

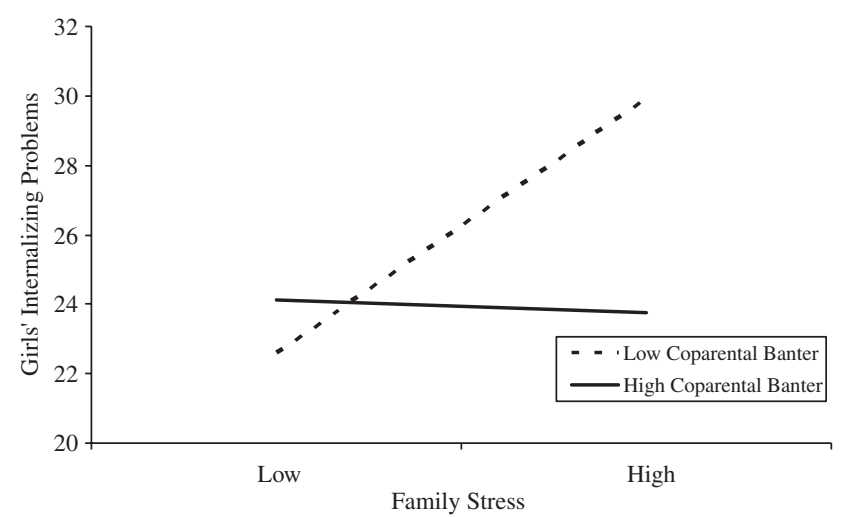

Figure 2. The interaction between family stress and coparental banter for daughters' internalizing problems.

for sons whose parents engaged in high levels of coparental banter $(\beta=0.39$, $p<0.05)$. Simple slope analyses revealed that regardless of the amount of coparental banter between parents, boys' internalizing problems increased as family stress increased. In contrast, for girls, the association between family stress and internalizing problems differed as a function of coparental banter. As shown in Figure 2, among couples low in coparental banter, there was a significant positive association between family stress and girls' internalizing problems ( $\beta=0.73, p<0.01)$. Among families where couples expressed high levels of coparental banter, the association between family stress and girls' internalizing problems was not significant $(\beta=-0.04, p=0.81)$. That is, high levels of coparental banter attenuated the association between family stress and girls' internalizing problems.

An interaction between coparental banter and child gender was significant for externalizing problems, $B=-3.39$, S.E. $=1.52, t=-2.23, p<0.05$, overall $R^{2}=0.24, F(7,96)=4.43, p<0.001$. As Figure 3 shows, a different association exists between coparental banter and children's externalizing problems for boys and girls. A significant negative association was found between coparental banter 


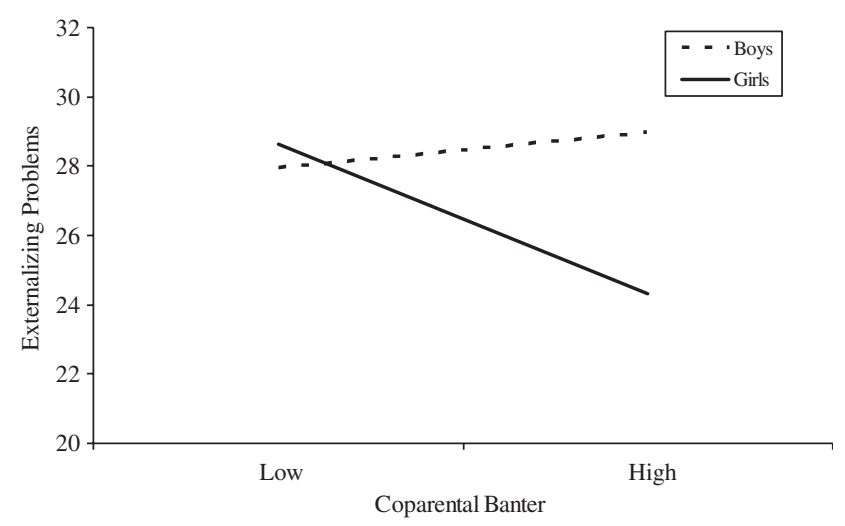

Figure 3. The interaction between coparental banter and child gender for externalizing problems.

and girls' externalizing problems $(\beta=-0.33, p<0.05)$ such that daughters whose parents engaged in more coparental banter exhibited fewer externalizing problems. The association between coparental banter and boys' externalizing problems was not significant $(\beta=0.08, p=0.53)$ indicating that coparental banter was not related to boys' behaviour.

\section{DISCUSSION}

This multi-method investigation was designed to examine toddlers' social-emotional adjustment in relation to family stress and family-level coparenting processes as well as whether the pattern of associations differed by child gender. Consistent with prior research, stress within the family environment was linked to children's poor adjustment (Crnic et al., 2005; Gaylord et al., 2003; Harrist \& Ainslie, 1998; Mahoney et al., 1997). Fewer associations emerged between familylevel coparenting processes and children's adjustment; however, coparenting processes contributed simultaneously and interactively to toddler adjustment in the current study. Though family harmony and coparental banter were moderately correlated in the current study, different patterns of findings emerged with respect to these family-level coparenting processes suggesting that these variables tapped unique dimensions of coparenting processes. Family harmony, which taps overall warmth and cooperation between parents, explained variance, along with family stress, in children's internalizing problems, whereas coparental banter, which appears to be tapping a more specific kind of humour between parents, interacted with family stress and child gender to contribute to children's adjustment. This study suggests that coparental banter or 'playful humour' between couples may be an important buffer against negative outcomes for toddlers, particularly for girls' behaviour problems.

In line with previous research that found support for family-level coparenting processes as unique predictors of children's outcomes when considered in combination with parenting (Belsky et al., 1997; Stright \& Neitzel, 2003), maternal well-being, and marital quality (McHale \& Rasmussen, 1998), moderate support was found for family harmony as a unique predictor of children's adjustment in the current study. Specifically, family harmony contributed to children's internalizing problems when family stress was considered. Children in families 
where family members were warm towards each other and the couples were cooperative and more similar in their levels of involvement with their child were reported to have fewer internalizing problems. Though this same finding was not replicated for coparental banter, it may be that family harmony was more directly related to children's adjustment because this composite assessed individual aspects of parent-child relationships that may be especially relevant to children's positive adjustment. Thus, harmonious family interactions may have important implications for children's behavioural adjustment.

Coparental banter did not contribute independently to children's adjustment; however, it contributed interactively. Child gender played a noteworthy role in delineating the nature of the associations among family stress, family-level coparenting processes, and children's behaviour problems such that different patterns of association emerged for male and female toddlers' internalizing and externalizing behaviours. For boys, the positive association between family stress and their internalizing behaviours was strong regardless of the amount of parents' coparental banter. This same association was also found for girls whose parents engaged in low levels of coparental banter; however, for girls whose parents engaged in more coparental banter, family stress and internalizing behaviours were not associated suggesting that coparental banter may serve an ameliorative function for girls in this case. Given that the family stress composite included parental ratings of marital conflict and that boys are generally found to be more vulnerable to marital conflict (Campbell, 2002), especially during middle childhood (Emery \& O'Leary, 1982; Kerig, 1996, 1999), the current finding may not be surprising. It is reasonable to speculate that toddler boys may be equally sensitive to overall family stress in such a way that family-level coparenting processes are unable to buffer boys from the detrimental effects of stress. Moreover, this finding seems compatible with previous research conducted with a sample of preadolescents, which found that boys under conditions of high stress were less protected by positive family characteristics (Masten et al., 1988). Similarly here, positive family-level processes-high levels of coparental banter-did not appear to provide the same compensation for boys as it did for girls exposed to high levels of family stress.

In contrast, parents' good-humoured, playful conversation moderated the positive association between family stress and daughters' internalizing problems. Though a strong relationship continued to exist between family stress and daughters' internalizing problems for couples who engaged in low levels of coparental banter, among couples who engaged in higher levels of coparental banter daughters' internalizing problems did not vary significantly with changing levels of family stress. In other words, high levels of family stress were not accompanied by increases in children's internalizing problems for couples who exhibited more 'playful humour' during the triadic interactions. Thus, it appears that high levels of coparental banter play an ameliorative function in the family such that daughters' adjustment may be less vulnerable to the negative effects of stressful family environments. Numerous studies have found that positive affect, including humour and affection, predicts marital quality and stability (Carstenson et al., 1995; Gottman et al., 1998). Specifically, Gottman and Levenson (1999) found that positive emotions may offset the expression of negative emotions during marital interactions and recent research by this group found that couples' positivity during their everyday interactions was also associated with their use of humour and affection during conflict discussions (Driver \& Gottman, 2004). Parents' use of humour has also been shown to contribute to parents' coping strategies and decreased levels of stress 
(Eisengart et al., 2003). Taken together, research suggests that humour is beneficial for individual well-being and marital quality. Positive affect, including humour, may be equally beneficial for family functioning and children's development, especially for daughters. More specifically, coparental banter or 'playful humour' during family freeplay may be indicative of the way in which couples approach conflicts and problems within their families. This type of humour may be used as a strategy to lighten negative parental emotions during conflicts and may actually help to diffuse tense situations between couples. In fact, this snapshot of family experiences may be representative of a repertoire of positive behaviour used across various family interactions to which children may be exposed. Thus, it appears that 'playful humour' between parents may offset the negative impact of stressful family situations on daughters' internalizing problems.

Child gender also interacted with coparental banter to predict externalizing behaviour problems. In contrast to the findings for internalizing problems, the patterns of associations held for children regardless of the amount of stress the families reported. Again, girls benefited more from higher levels of coparental banter such that as banter between parents increased, girls exhibited fewer externalizing problems. In contrast, boys' externalizing behaviours were not related to the amount of 'playful humour' between couples and, in fact, regardless of coparental banter, boys' externalizing behaviours remained elevated. Again, boys seem to be unaffected by parents' interactions in that positive family-level coparenting processes did not covary with boys' externalizing problems, thus, leading us to speculate that girls might somehow be more attentive than boys to positive ongoing family dynamics and interactions between parents, while boys may be more attentive to negative ones. This explanation is in line with an idea put forth by Davies and Lindsay (2001) in which they suggested that because of girls' greater concern for harmonious interpersonal relations they may be more aware of how couples resolve conflict. Though speculative, given the young age of children in the current study, these findings suggest that boys' and girls' externalizing behaviours may be differentially related to positive interactions between parents such that girls may benefit more when parents' interactions are characterized by positive affect. Although there is very little research on the differential effects of humour with respect to gender, several studies on adults do support the notion that humour may be more protective for women than for men. For example, greater use of humour as a coping strategy during adulthood was linked to lower levels of depression in women but not men (Overholser, 1992). In addition, humour also moderated the association between stress and depression (Martin \& Lefcourt, 1983) as well as being linked to greater marital satisfaction, social relations, and happiness for wives but not for husbands (Lefcourt \& Martin, 1986).

\section{Limitations and Future Directions}

In addition to broadening our understanding of the role that everyday stress and conflict within the family have on family functioning and children's adjustment, the current study replicated prior research that found additive and interactive effects for family-level coparenting processes in the prediction of children's adjustment. This investigation, however, is not without its limitations. First, the sample we utilized for the current study was predominantly EuropeanAmerican, middle-class couples drawn from a community population. Even though there was considerable variation in the variables that comprised our 
family stress composite, these dual-earner couples lived in a relatively rural area in central Pennsylvania and shared the responsibility of providing income for the family. Thus, the findings from the current study are limited in their generalizability. Future research should consider the nature of the associations among family stress, coparenting processes, and children's development within ethnically and economically diverse samples. Positive coparenting processes may play a more critical role in samples at a greater risk for high levels of stress.

Characteristics of the sample (e.g. middle-class, dual-earner couples) may also have limited our ability to code competitive and hostile coparenting interactions in the current investigation; however, as our findings suggest these couples may use banter as a coping mechanism to diffuse negativity in the coparenting relationship. Other researchers have been successful in coding hostility (McHale, 1995) and undermining coparenting (Schoppe et al., 2001), even within community samples; thus, the nature of the interaction task used in this investigation may have precluded us from coding coparenting negativity. We asked the parents 'to play with their child as they normally would' thereby creating a freeplay session that may have allowed parents to disengage from the interaction instead of expressing negativity towards the other parent. To bring out more negativity, it may have been necessary to design a paradigm or task that would have been more 'stressful'. For example, an interaction task that required the parents to work together to help their child accomplish a specific objective may have provoked more negativity between the partners. Thus, future studies would benefit from paradigms designed to 'stress' the child and the parents.

The data for the current study were gathered contemporaneously limiting our ability to establish causal relationships among the constructs examined. Though we suggest that family stress precedes or sets the stage for child adjustment problems, it may also be the case that children with greater adjustment problems present more difficulties and greater stress for parents. More than likely, the associations examined here represent bidirectional, dynamic processes within the family (Bell, 1968). Because of the difficulty in untangling these processes, research in this area would benefit greatly from longitudinal data designed to specifically examine stress within the family, coparenting processes, and children's development over time.

Finally, in the current study, parents reported on their marital conflict, role overload, parenting hassles, and children's behaviour. Though we relied on parents' reports, we created a robust composite of family stress that included mothers' and fathers' perceptions of stress related to multiple domains and we averaged across mothers' and fathers' reports of child adjustment thereby reducing the likelihood that the associations between family stress and child adjustment are due simply to shared method variance across one reporter. Parents are probably the most accurate reporters of their experiences of stress given the individual nature of this construct; however, future investigations in this area might benefit from child adjustment data gathered either from another reporter (i.e. a teacher) or through observational methods.

In sum, this multi-method investigation utilized maternal and paternal reports, along with observational data of family interactions, to examine the associations among family stress, family-level coparenting processes, parent/ child relations, and children's adjustment. Extending research on family stress and children's adjustment, links were found between the accumulation of mothers' and fathers' stress related to their roles as marital partners, parents, and workers and children's development. Consistent with the research to date on coparenting processes, family-level coparenting processes in the current study 
contributed uniquely (Belsky et al., 1997; McHale \& Rasmussen, 1998; Stright \& Neitzel, 2003) and interactively (Schoppe et al., 2001; Stright \& Neitzel, 2003) to children's developmental outcomes. Findings from the current investigation underscore the importance of 'playful humour' or coparenting banter between parents in understanding toddlers' social development as well as the protective role coparenting banter may play in shielding children, especially girls, from poor behavioural adjustment.

\section{Note}

1. During an earlier investigation, the authors tested a series of mediation models where coparenting processes were examined as mediators of the associations between family stress and child adjustment; however, these findings were not significant.

\section{ACKNOWLEDGEMENTS}

This research was funded by a grant (HD31540) from the National Institute of Child Health and Human Development. The first author was supported by dissertation funding from the Department of Human Development and Family Studies at the Pennsylvania State University and by the University of Michigan NICHD Developmental Training Grant (T32 HD007109). We would like to thank the families that participated in the Health and Development Project for their time and commitment to this research. We would also like to extend our gratitude to the Health and Development Project staff for their dedication and attentiveness to data collection and coding.

\section{REFERENCES}

Achenbach, T. M., \& Edelbrock, C. S. (1981). Behavioral problems and competencies reported by parents of normal and disturbed children aged four through sixteen. Monographs of the Society for Research in Child Development, 46 (1, Serial No. 188).

Aiken, L. S., \& West, S. G. (1991). Multiple regression: Testing and interpreting interactions. Newbury Park, CA: Sage.

Barnett, R. C. (1994). Home-to-work spillover revisited: A study of full-time employed women in dual-earner couples. Journal of Marriage and the Family, 56, 647-656.

Barnett, R. C., Marshall, N. L., \& Pleck, J.H. (1992). Men's multiple roles and their relationship to men's psychological distress. Journal of Marriage and the Family, 54, 358-367.

Bell, R. Q. (1968). A reinterpretation of the direction of effects in studies of socialization. Psychological Review, 75, 81-95.

Belsky, J. (1984). The determinants of parenting: A process model. Child Development, 55, 83-96.

Belsky, J., \& Hsieh, K. (1998). Patterns of marital change during the early childhood years: Parent personality, coparenting, and division-of-labor correlates. Journal of Family Psychology, 12, 511-528.

Belsky, J., Putnam, S., \& Crnic, K. (1997). Coparenting, parenting, and early emotional development. In J. McHale, \& P. Cowan (Eds.), Understanding how family-level dynamics affect children's development: Studies of two-parent families. New Directions for Child Development, 74, 45-55.

Bohen, H. B., \& Viveros-Long, A. M. (1981). Balancing jobs and family life: Do flexible work schedules help. Philadelphia: Temple University Press. 
Braiker, H. B., \& Kelly, H. H. (1979). Conflict in the development of close relationships. In R. Burgess, \& T. Huston (Eds.), Social exchange in developing relationships (pp. 135-168). New York: Academic Press.

Brody, G. H., Flor, D. L., \& Neubaum, E. (1998). Coparenting processes and child competence among rural African-American families. In M. Lewis, \& C. Feiring (Eds.), Families, risk, and competence (pp. 227-243). Mahwah, NJ: Erlbaum.

Buehler, C., Anthony, C., Krishnakumar, A., \& Stone, G. (1997). Interparental conflict and youth problem behavior: A meta-analysis. Journal of Child and Family Studies, 6, 223-247. Campbell, S. B. (2002). Behavior problems in preschool children. New York: Guilford Press.

Carstenson, L., Gottman, J., \& Levenson, R. (1995). Emotional behavior in long-term marriage. Psychology and Aging, 10, 140-149.

Cox, M. J., \& Paley, B. (2003). Understanding families as systems. Current Directions in Psychological Science, 12, 193-196.

Cox, M. J., Owen, M. T., Lewis, J. M., \& Henderson, V. K. (1989). Marriage, adult adjustment, and early parenting. Child Development, 60, 1015-1024.

Creasey, G. L., \& Jarvis, P. A. (1994). Relationships between parenting stress and developmental functioning among 2-year-olds. Infant Behavior and Development, 17, 423-429.

Creasey, G. L., \& Reese, M. (1996). Mothers' and fathers' perceptions of parenting hassles: Associations with psychological symptoms, nonparenting hassles, and child behavior problems. Journal of Applied Developmental Psychology, 17, 393-406.

Crnic, K. A., \& Greenberg, M. T (1990). Minor parenting stresses with young children. Child Development, 61, 1628-1637.

Crnic, K. A., Gaze, C., \& Hoffman, C. (2005). Cumulative parenting stress across the preschool period. Infant and Child Development, 14, 117-132.

Crouter, A. C., Bumpass, M. F., Head, M. R., \& McHale, S. M. (2001). Implications of overwork and overload for the quality of men's family relationships. Journal of Marriage and the Family, 63, 404-416.

Cummings, M. E., \& Davies, P. (1996). Emotional security as a regulatory process in normal development and the development of psychopathology. Development and Psychopathology, 8, 123-139.

Davies, P. T., \& Lindsay, L. L. (2001). Does gender moderate the effects of marital conflict on children. In J. H. Grych, \& F. D. Fincham (Eds.), Interparental conflict and child development (pp. 64-97). Cambridge, UK: Cambridge University Press.

Deater-Deckard, K., \& Scarr, S. (1996). Parenting stress among dual earner mothers and fathers: Are there gender differences? Journal of Family Psychology, 10, 45-59.

Driver, J. L., \& Gottman, J. M. (2004). Daily marital interactions and positive affect during marital conflict among newlywed couples. Family Process, 43, 301-314.

Eisengart, S. P., Singer, L. T., Fulton, S., \& Baley, J. E. (2003). Coping and psychological distress in mothers of very low birth weight young children. Parenting, Science and Practice, 3, 49-72.

Emery, R. E., \& O'Leary, K. D. (1982). Children's perceptions of marital discord and behavior problems of boys and girls. Journal of Abnormal Child Psychology, 10, 11-24.

Gaylord, N. K., Kitzmann, K. M., \& Lockwood, R. L. (2003). Child characteristics as moderators of the association between family stress and children's internalizing, externalizing, and peer rejection. Journal of Child and Family Studies, 12, 201-213.

Gottman, J. M., \& Levenson, R. W. (1999). What predicts change in marital interaction over time? A study of alternative models. Family Process, 38, 143-158.

Gottman, J. M., Coan, J., Carrere, S., \& Swanson, C. (1998). Predicting marital happiness and stability from newlywed interactions. Journal of Marriage and the Family, 60, 5-22.

Harrist, A. W., \& Ainslie, R. C. (1998). Marital discord and child behavior problems: Parent-child relationship quality and child interpersonal awareness as mediators. Journal of Family Issues, 19, 140-163.

Hetherington, E. M. (1984). Stress and coping in children and families. New Directions for Child Development, 24, 7-33.

Johnston, J. R., Gonzalez, R., \& Campbell, L. E. (1987). Ongoing post-divorce conflict and child disturbance. Journal of Abnormal Child Psychology, 15, 165-173.

Jouriles, E. N., Bourg, W. J., \& Farris, A. M. (1991). Marital adjustment and child conduct problems: A comparison of the correlation across subsamples. Journal of Consulting and Clinical Psychology, 59, 354-357. 
Katz, L., \& Gottman, J. (1996). Spillover effects of marital conflict: In search of parenting and coparenting mechanisms. In J. McHale, \& P. Cowan (Eds.), Understanding how family-level dynamics affect children's development: Studies of two-parent families. New Directions for Child Development, 74, 57-76.

Kerig, P. K. (1996). Assessing the links between interparental conflict and child adjustment: The conflicts and problem-solving scales. Journal of Family Psychology, 10, 454-473.

Kerig, P. K. (1999). Gender issues in the effects of exposure to violence on children. Journal of Emotional Abuse, 2, 87-105.

Kerig, P. K., Cowan, P. A., \& Cowan, C. P. (1993). Marital quality and gender differences in parent-child interaction. Developmental Psychology, 29(6), 931-939.

LaFreniere, P. J., Dumas, J. E., Capuano, F., \& Dubeau, D. (1992). Development and validation of the Preschool Socioaffective Profile. Psychological Assessment, 4, 442-450.

Lamb, M. E. (Ed.) (2004). The role of the father in child development. Hoboken, NJ: Wiley.

Lee, M., Vernon-Feagans, L., Vazquez, A., \& Kolak, A. (2003). The influence of family environment and child temperament on work/family role strain for mothers and fathers. Infant and Child Development, 12, 421-439.

Lefcourt, H. M., \& Martin, R. A. (1986). Humor and life stress: Antidote to adversity. New York: Springer/Verlag.

Lichtenstein, P., Ganiban, J., Neiderhiser, J. M., Pedersen, N. L., Hansson, K., Cederblad, M., et al. (2003). Remembered parental bonding in adult twins: Genetic and environmental influences. Behavior Genetics, 33, 397-408.

Mahoney, A., Jouriles, E. N., \& Scavone, J. (1997). Marital adjustment, marital discord over childrearing, and child behavior problems: Moderating effects of child age. Journal of Clinical Child Psychology, 26, 415-423.

Manlove, E. E., \& Vernon-Feagans, L. (2002). Caring for infant daughters and sons in dualearner households: Maternal reports of father involvement in weekday time and tasks. Infant and Child Development, 11, 305-320.

Martin, R. A., \& Lefcourt, H. M. (1983). Sense of humor as a moderator of the relationship between stressors and moods. Journal of Personality and Social Psychology 45, 1313-1324.

Masten, A. S., Garmezy, N., Tellegen, A., Pellegrini, D. S., Larkin, K., Larsen, A. (1988). Competence and stress in school children: The moderating effects of individual and family qualities. Journal of Child Psychology and Psychiatry, 29, 745-764.

McHale, J. P. (1995). Coparenting and triadic interactions in infancy: The roles of marital distress and child gender. Developmental Psychology, 31, 985-996.

McHale, J. P., \& Rasmussen, J. L. (1998). Coparental and family group-level dynamics during infancy: Early family precursors of child and family functioning during preschool. Development and Psychopathology, 10, 39-59.

McHale, J. P., Kuersten-Hogan, R., \& Lauretti, A. (2001). Evaluating coparenting and family-level dynamics during infancy and early childhood: The coparenting and family rating system. In P. K. Kerig, \& K. M. Lindahl (Eds.), Family observational coding systems (pp. 151-170). Mahwah, NJ: Erlbaum.

Minuchin, S. (1974). Families and family therapy. Cambridge, MA: Harvard University Press.

Overholser, J. C. (1992). Sense of humor when coping with life stress. Personality and Individual Differences, 13, 799-804.

Owen, M. T., \& Cox, M. J. (1997). Marital conflict and the development of infant-parent attachment relationships. Journal of Family Psychology, 11, 152-164.

Reid, W. J., \& Crisafulli, A. (1990). Marital discord and child behavior problems: A metaanalysis. Journal of Abnormal Child Psychology, 18, 105-117.

Sameroff, A., Seifer, R., \& McDonough, S. C. (2004). Contextual contributors to the assessment of infant mental health. In R. DelCarmen-Wiggins, \& A. Carter (Eds.), Handbook of infant, toddler, and preschool mental health assessment (pp. 61-76). New York: Oxford University Press.

Schoppe, S. J., Mangelsdorf, S. C., \& Frosch, C. A. (2001). Coparenting, family process, and family structure: Implications for preschoolers' externalizing behavior problems. Journal of Family Psychology, 15, 526-545.

Stright, A. D., \& Neitzel, C. (2003). Beyond parenting: Coparenting and children's classroom adjustment. International Journal of Behavioral Development, 27, 31-40.

Talbot, J. A., \& McHale, J. P. (2004). Individual parent adjustment moderates the relationship between marital and coparenting quality. Journal of Adult Development, 11, 191-205. 
Tamis-LeMonda, C. S., \& Cabrera, N. (2002). Handbook of father involvement: Multidisciplinary perspectives. Mahwah, NJ: Erlbaum.

Voydanoff, P. \& Donnelly, B. W. (1999). Multiple roles and psychological distress: The intersection of the paid worker, spouse, and parent roles with the role of the adult child. Journal of Marriage and the Family, 61, 725-738.

Webster-Stratton, C. (1990). Stress: A potential disruptor of parent perceptions and family interactions. Journal of Clinical Child and Adolescent Psychology, 19, 302-312.

Zahn-Waxler, C. (1993). Warriors and worriers: Gender and psychopathology. Development and Psychopathology, 5, 79-90. 